\title{
Overview of the TOPEX/Poseidon Platform Harvest Verification Experiment
}

\author{
CHARLES S. MORRIS \\ STEVEN J. DiNARDO \\ EDWARD J. CHRISTENSEN \\ Jet Propulsion Laboratory \\ California Institute of Technology \\ Pasadena, California, USA
}

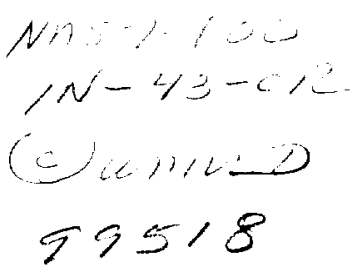

\begin{abstract}
An overview is given of the in situ measurement system installed on Texaco's Platform Harvest for verification of the sea level measurement from the TOPEX/Poseidon satellite. The prelaunch error budget suggested that the total root mean square (RMS) error due to measurements made at this verification site would be less than $4 \mathrm{~cm}$. The actual error budget for the verification site is within these original specifications. However, evaluation of the sea level data from three measurement systems at the platform has resulted in unexpectedly large differences between the systems. Comparison of the sea level measurements from the different tide gauge systems has led to a better understanding of the problems of measuring sea level in relatively deep ocean. As of May 1994, the Platform Harvest verification site has successfully supported 60 TOPEXIPoseidon overflights.
\end{abstract}

Keywords satellite altimetry, verification, sea level, TOPEX, Poseidon

TOPEX/Poseidon is a satellite mission that uses altimetry to make precise measurements of sea level; its primary goal is the study of global ocean circulation. This mission is jointly conducted by the U.S. National Aeronautics and Space Administration (NASA) and the French space agency, Centre National d'Etudes Spatiales (CNES). A description of the satellite instruments and mission is given by Zieger et al. 1995.

TOPEX/Poseidon was launched on August 10,1992, and was placed in its operational orbit through a series of maneuvers spanning approximately 6 weeks. The first complete 9.9-day cycle of operational data (cycle 1) commenced on September 23. To date, TOPEX/Poseidon is providing researchers with the most accurate sea level measurements ever obtained from an altimetric satellite. To verify the performance of the satellite

The TOPEX/Poseidon Science Verification Team gratefully acknowledges the assistance and cooperation of Texaco and, in particular, the personnel of the Ventura, California office and on Platform Harvest (Texaco and contractors). Without their support and advice, this work and its success would not have been possible. Special thanks go to Richard Gunder of VECO for assisting us many times at the platform when we were unable to be there. This work was performed at the Jet Propulsion Laboratory, California Institute of Technology, under contract with the National Aeronautics and Space Administration.

Address correspondence to Charles S. Morris, MS 300-319, Jet Propulsion Laboratory, 4800 Oak Grove Drive, Pasadena, CA 91109 , USA. 
system, NASA and CNES developed a joint verification plan (Christensen and Menard, 1992) that included investigations from the scientific community and the TOPEX/Poseidon Project. A major component of this effort is "on-site" verification: the comparison of the satellite data with an extensive series of in situ measurements made at a verification site. Both NASA and CNES instrumented separate verification sites. The CNES verification site was located at Lampione, a small islet $18 \mathrm{~km}$ west of Lampedusa Island in the Mediterranean Sea (see Menard et al., 1994). The NASA verification site is an oil platform off of Point Conception. California. This paper and the associated papers in this special issue will focus on the experiment design, implementation, and results obtained at the NASA verification site.

This is not the first time on-site verification has been conducted for satellite altimeters. Previous verification work has been performed for SEASAT (Kolenkiewicz and Martin, 1982) and ERS-1 (Francis, 1993). In terms of the absolute accuracy required, the TOPEX/ Poseidon on-site verification effort is the most ambitious activity of this type ever attempted.

\section{On-Site Verification and the Closure Analysis}

The purpose of on-site verification is to collect, in a single location, the in situ data necessary to independently verify the performance of the TOPEX/Poseidon measurement system. From these data, an estimate is made of the system bias, usually expressed in terms of altimeter bias. i.e., the difference between the expected altimeter-to-ocean distance and the actual distance measured by the altimeter. Bias is of interest when more than one altimeter's data are compared to evaluate long-term trends in the ocean and also as a measure of our understanding of the operation of the altimeter and the processing of the data. Of greater importance is the temporal change in the bias (called bias drift) which, if significant, could have a serious impact on the scientific results.

On-site verification requires an independent measure of the altimeter-to-ocean distance. To obtain this independent value, in situ sea level must be accurately tied to the same reference frame as the satellite. This is accomplished by combining a number of measurements obtained using different techniques. First, the position of the satellite over the verification site must be determined to within a few centimeters in the vertical by applying orbit determination techniques to laser and other tracking data. This establishes the position of the satellite in the reference frame of the lasers. The location of the verification site relative to the lasers is estimated using global positioning system (GPS) receivers. Finally, vertical measurements are made from the GPS antenna at the verification site to the sea level measurement instruments. This ties the verification site sea level measurements to the same reference frame as the lasers and the satellite. An estimate of the satellite/sea level distance is obtained using triangulation and is compared to the altimeter measurement. We call this analysis closure. This concept is illustrated in Figure $I$ and an in-depth discussion is provided by Christensen et al. (1989).

\section{Verification Site Selection}

Several factors must be considered when selecting a verification site. A primary requirement is that it be located far enough from land to avoid contaminating the altimeter signal. In addition, the site itself must be small enough as to not affect the altimeter's return signal reflected from the ocean surface. The logical choices for a verification site are limited to a small island or an oil platform. An evaluation of several potential locations 


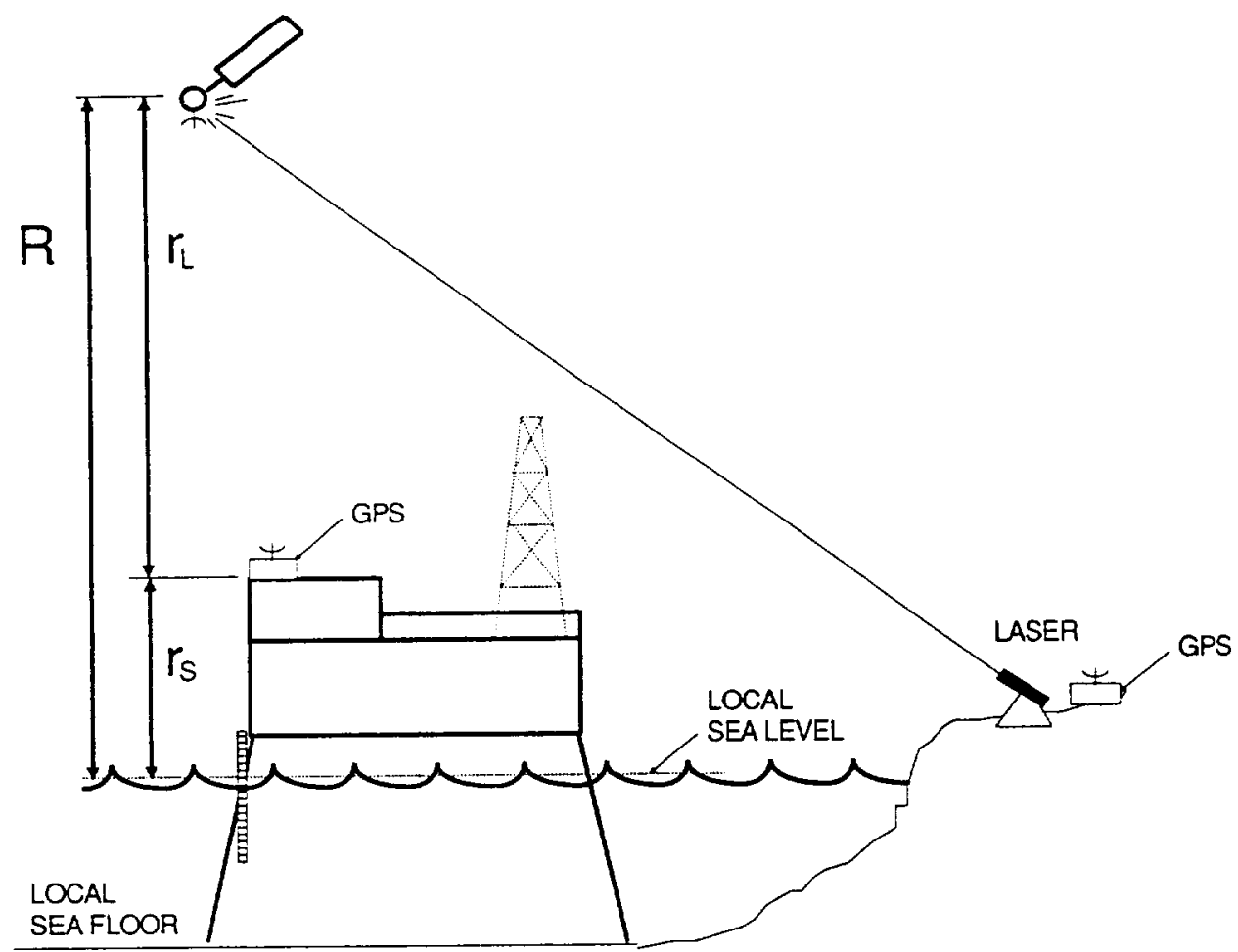

Figure 1. The concept of on-site verification. The closure analysis compares the altimeter-to-ocean distance estimated from in situ measurements $\left(r_{\mathrm{t}}+r_{\mathrm{s}}\right)$ with the altimeter measurement $(R)$, where $r_{\mathrm{t}}$ is the height of the satellite with respect to the benchmark on the platform and $r_{\mathrm{s}}$ is the distance from the benchmark to local sea level.

for the NASA verification site, including Bermuda, oil platforms in the Gulf of Mexico, and oil platforms off of California, was made. Several criteria were used in the selection process, including the available laser coverage, anticipated accuracy of the in situ observations, logistical considerations, and cost.

The decision was made to instrument an oil platform located off of Point Conception, California. Several oil platforms were then considered. Texaco's Platform Harvest, located $11 \mathrm{~km}$ south-southwest of Point Arguello and $19.5 \mathrm{~km}$ west of Point Conception, California, was finally chosen as the NASA verification site (see Figures 2 and 3 ). The selection was based on the excellent laser coverage (see Figure 4) and logistical considerations. In March 1991, a memorandum of understanding was signed between Texaco USA, Inc., and JPL permitting the installation of instrumentation at the platform.

\section{Verification Site Instrumentation}

The verification work performed at Platform Harvest is a collaborative effort among the National Oceanic and Atmospheric Administration/National Ocean Service (NOAA/ NOS), the University of Colorado (CU), and the Jet Propulsion Laboratory (JPL). The design and installation of the instrumentation and equipment used in this experiment had 


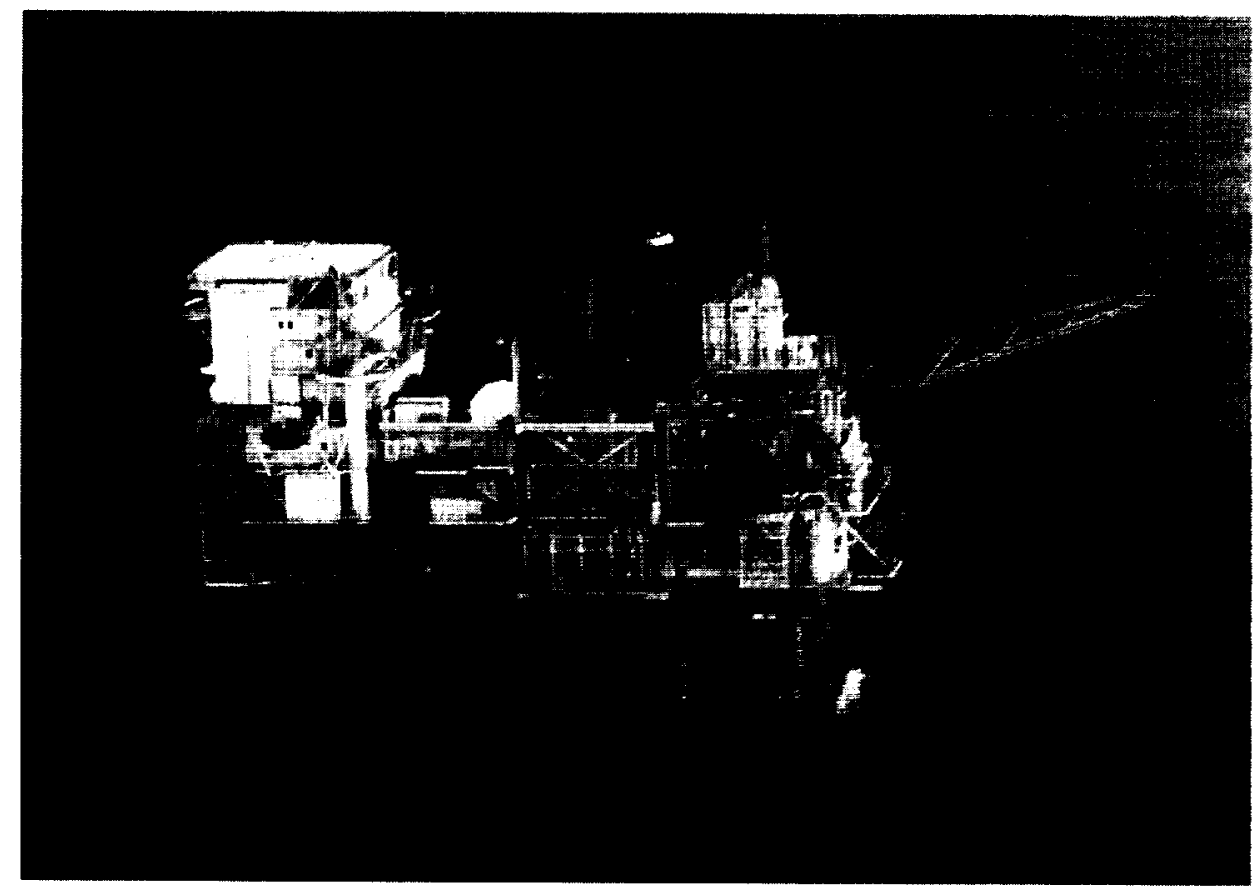

Figure 2. A view of Texaco's Platform Harvest, located off of Point Conception, California, looking toward the northeast.

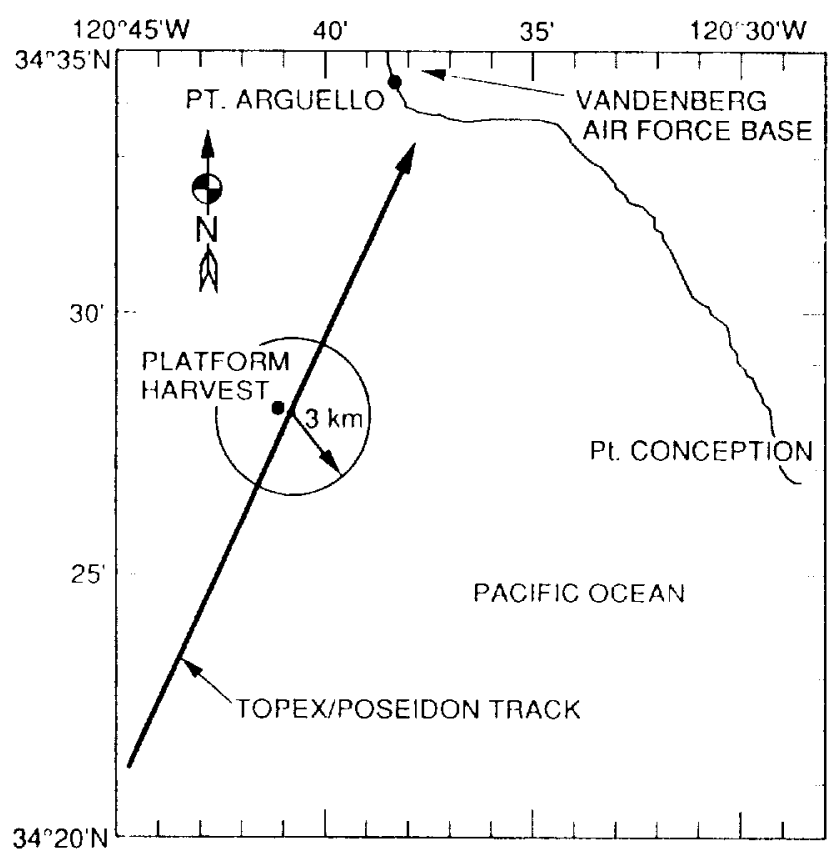

Figure 3. The location of the NASA verification site off the coast of the California coast. The line shows the ascending TOPEX/Poseidon ground track and the circle illustrates an idealized altimeter measurement footprint. 


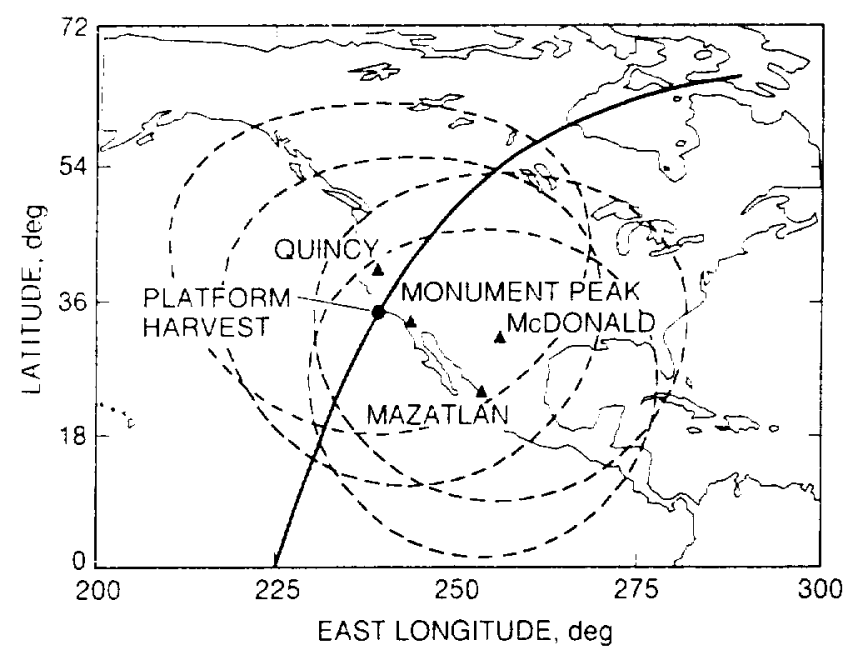

Figure 4. Laser coverage (dashed circles) for the NASA verification site overfights.

to meet various constraints, some of which conflicted with one another. These included satisfying the observational requirements (e.g., sky visibility), oil platform safety requirements, platform space requirements, and the need to conduct the experiment without interfering with oil platform operations. Table 1 summarizes the major milestones of the installation of the verification instrumentation at Platform Harvest.

The instrumentation installed at Platform Harvest were selected to measure those parameters required for the closure analysis. These instruments are summarized in Table 2 and their relative location on the platform is illustrated in Figure 5. Because the primary goal of the experiment was to measure sea level, three different types of sea level measurement systems were installed to monitor the level of the ocean. NOAA/NOS supplied a next-generation water leveling measuring system (NGWLMS) that includes two water level sensors: a self-calibrating acoustic device with an echo-timing receiver, and a backup pressure transducer/nitrogen bubbler combination. Both of these systems provide sea level estimates averaged over $181 \mathrm{~s}$ once every $6 \mathrm{~min}$. In addition, the acoustic system has the optional capability to record sea level in a high-rate or tsunami mode which produces a sea level measurement every $2 \mathrm{~s}$. CU provided the third system consisting of three pressure transducers. Two pressure transducers are mounted below the water and the third measures atmospheric pressure. This arrangement permits the two submerged pressure transducers to be intercompared. The third transducer serves as a backup to the NOAA/NOS barometer for measuring atmospheric pressure. The CU system provides sea level estimates about once per second during satellite overflights and approximately every $2 \mathrm{~min}$ at other times. The NOAA/NOS and CU systems are discussed in detail by Gill et al. (1995) and Kubitschek et al. (1995), respectively.

The platform's location relative to the laser sites is obtained by operating a Turbo Rogue GPS receiver at the platform. In addition, the GPS receiver also provides an estimate of the total electron content (TEC) through a vertical column above the platform. The derived TEC value is one of the checks made on the ionospheric correction, which is applied to the altimeter measurement. Further description of the GPS receiver is given 
Table 1

Installation of in situ verification instrumentation on platform harvest significant events

1990

May Platform Harvest selected as the NASA verification site.

August One-week platform experiment testing the feasibility of operating a GPS receiver and water vapor radiometer at the platform.

December First vertical platform survey between the GPS and sea level reference point conducted by NOAA/NOS.

1991

March MOU signed between Texaco and JPL.

June Walkway installed to permit access to one of the sea level risers.

December Steel risers, which house the sea level instrumentation, are installed by divers.

1992

April JPL equipment shed is installed.

May NOAA/NOS and CU sea level instrumentation commences operation. NOAA/NOS ancillary instrumentation is installed. NOAA/NOS performs the second vertical platform survey.

June GPS receiver is installed.

July Water vapor radiometer begins taking data.

August TOPEX/Poseidon is launched on the 10 th.

September First TOPEX/Poseidon overflight occurred on the 24th.

by Purcell et al. (1995) and the TEC comparison at the platform is discussed by Christensen et al. (1994).

Although the location of Platform Harvest in relation to land does not affect the altimeter signal, it was anticipated that land would contaminate the Topex microwave radiometer (TMR) observations during TOPEX/Poseidon overflights of the platform, because of TMR's significantly larger footprint. This was, in fact, what occurred. The primary purpose of TMR is to provide a columnar atmospheric water vapor estimate so that the altimeter observations can be corrected for the affects of water vapor (the wet tropospheric correction). Based on an analysis by Keihm (private communication), the TMR brightness temperatures are rapidly increasing as the satellite passes over Harvest with excesses typically $20 \mathrm{~K}$ for the 18 - and $21-\mathrm{GHz}$ channels and $12 \mathrm{~K}$ for the $37-\mathrm{GHz}$ channel. While these brightness temperature increases do compensate each other to some degree, the retrieved wet tropospheric path delay at the platform, derived from TMR, is typically $1-2 \mathrm{~cm}$ in error. To eliminate this uncertainty, an upward-looking water vapor radiometer (WVR) provides an alternate measurement of water vapor at Platform Harvest. A JPL J-Series WVR (see Keihm and Ruf, 1995) is mounted near the platform's heliport to perform this task. 
Table 2

NASA verification site instrumentation

\begin{tabular}{|c|c|c|}
\hline Instrument & Parameter & Responsible \\
\hline $\begin{array}{l}\text { Sea level instrumentation } \\
\text { NGWLMS" - acoustic } \\
\text { NGWLMS" }-\mathrm{N}_{2} \text { bubbler } \\
\text { Pressure transducers }\end{array}$ & Sea level & $\begin{array}{l}\text { NOAA/NOS } \\
\text { NOAA/NOS } \\
\text { Univ. of Colorado }\end{array}$ \\
\hline $\begin{array}{l}\text { Rogue global positioning } \\
\text { system (GPS) receiver }\end{array}$ & $\begin{array}{l}\text { Position and columnar } \\
\text { total electron content }\end{array}$ & $\mathrm{JPL}$ \\
\hline Water vapor radiometer & Columnar water vapor & JPL \\
\hline Barometer & Atmospheric pressure & NOAA/NOS \\
\hline Hygrometer & Relative humidity & NOAA/NOS \\
\hline Thermometer & Atmospheric temperature & NOAA/NOS \\
\hline $\begin{array}{l}\text { Ancillary ocean } \\
\text { instrumentation }\end{array}$ & $\begin{array}{l}\text { Water temperature; } \\
\text { water conductivity }\end{array}$ & NOAA/NOS \\
\hline
\end{tabular}

"NGWLMS = next-generation water level measurement system.

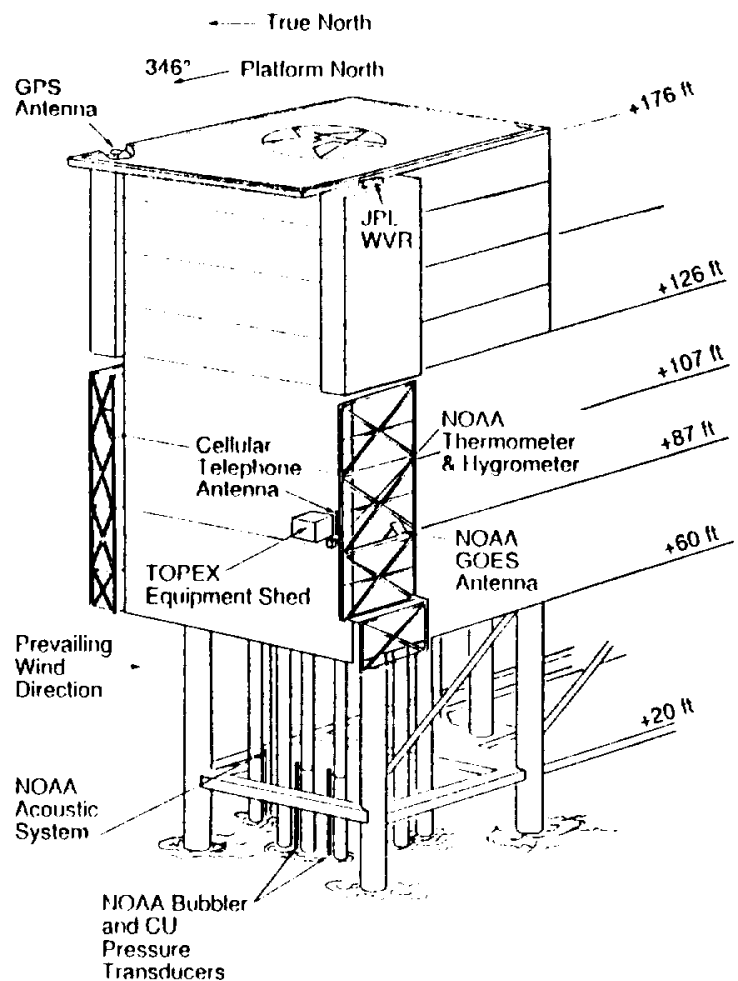

Figure 5. Location of the verification instrumentation on Platform Harvest. 
Ancillary measurements of relative humidity, barometric pressure, water temperature, water conductivity, and air temperature are made by NOAA/NOS instrumentation. Some of these measurements, such as the barometric pressure, water temperature, and conductivity, are crucial to the proper reduction of the pressure transducer sea level data (Kubitschek et al., 1995).

The computers associated with the verification instrumentation at the platform are housed in a small custom-made equipment shed. Other units in the shed provide clean power and communications via satellite (NOAA/NOS data only) and cellular telephone. The importance of providing clean power by using an uninterruptible power supply (UPS) cannot be overstated. The platform power is supplied by turbine generators, and momentary outages occur when the configuration of on-line generators is modified. In addition, longer outages sometimes occur during specific platform operations. Use of cellular telephone and satellite communication allows the verification experiment to be totally independent of the platform's microwave telephone link. Remote, real-time monitoring and configuration of each system computer are possible.

Although the initial satellite overflights had verification team personnel at the platform to monitor the instrumentation, data collection during the overflights was soon monitored remotely. Most of the data collection systems are automatic, requiring no manual intervention except to download the data. Data transmission off the platform is even handled automatically for the GPS and NOAA/NOS systems.

\section{Verification Site Error Budget}

Table 3 presents the prelaunch error budget for the NASA verification site. The errors specified are for a single overflight. The error budget was derived from calculation (i.e., thermal expansion), measurement (i.e., platform sway), and expert opinion (i.e., GPS and sea level measurement accuracy). Potential errors included both fixed and variable measurement errors, as well as errors resulting from changes in the platform. For instance, the location of the oil platform relative to the lasers is dependent on the accuracy of the GPS measurements. It is estimated that there is the potential for a fixed error (offset or bias) of up to $2.0 \mathrm{~cm}$. However, the variable error (from one overflight to the next) for the tie between the lasers and the platform is expected to be negligible.

There is the potential for vertical changes resulting from platform sway. The motion of the platform has been a significant concern since Platform Harvest was selected as the NASA verification site. Sitting in 670 feet of water, the platform is nearly as large as the Eiffel Tower. Wind and wave action can produce a noticeable sway. The critical issue for verification is the effect of the sway on the vertical location of the verification instruments. CU has conducted an experiment at Platform Harvest using an accelerometer designed to measure vertical acceleration and, thus, motion. This experiment occurred during high wind $(30+\mathrm{mps})$ and wave (up to $12 \mathrm{~m})$ conditions. The resulting vertical motion was about $1 \mathrm{~cm}$. During less severe conditions, the motion was found to be considerably less. Under "normal" conditions, the motion of the platform is expected to be $0.5 \mathrm{~cm}$ or less.

The vertical survey, which ties the GPS antenna to the sea level instruments, also may have a fixed measurement error and a variable error due to thermal expansion of the platform. This vertical distance of about $45 \mathrm{~m}$ is difficult to obtain because the measurement must be made down narrow stairways that are exposed to the wind: and the platform itself is swaying, which affects the leveling of the surveying instruments. Despite these 
Table 3

Pre-launch verification site error budget

\begin{tabular}{llc}
\hline \multicolumn{1}{c}{ Source } & Fixed $(\mathrm{cm})$ & Variable $(\mathrm{cm})$ \\
\hline GPS survey & & \\
Survey error & 2.0 & 0.0 \\
Platform sway & 0.0 & 0.5 \\
Thermal expansion of platform (below water line) & 0.0 & 0.5 \\
Other vertical changes & $0.0^{\prime \prime}$ & 0.0 \\
Platform survey & & \\
$\quad$ Survey error & 0.5 & 0.0 \\
Thermal expansion of platform (above water line) & 0.0 & 1.0 \\
Sea level measurement & & \\
Instrument zero & 0.0 & 0.0 \\
Instrument noise & 0.0 & 1.0 \\
Geoid crosstrack variability & 0.0 & 0.5 \\
Ocean spatial variability & 0.0 & 2.0 \\
RSS total & 2.06 & 2.60 \\
RSS total (fixed + variable): & & 3.32 \\
\hline
\end{tabular}

"At the time of the GPS survey. May change (increase) between surveys.

problems, NOAA/NOS personnel surveyed this vertical distance with an estimated accuracy of $4 \mathrm{~mm}$.

There are a number of measurement errors associated with the determination of sea level. The largest was originally thought to be the variable error resulting from the spatial variability of the ocean within the altimeter footprint. This error results from comparing a point in situ measurement with the altimeter observation averaged over a $3.1-\mathrm{km}$ (pulselimited width) $\times 5.8-\mathrm{km}$ (alongtrack) footprint. The cross-track geoid error results from overflight-to-overflight variations in the satellite's groundtrack, which is maintained to within $\pm 1.0 \mathrm{~km}$, and from uncertainties in the geoid in the vicinity of the oil platform. It is expected that this potential error will be reduced as additional overflight data are obtained.

Of particular note is the "instrument noise" error. Prior to launch, the consistent measurement of sea level was not considered to be a problem; an accuracy of better than $1 \mathrm{~cm}$ was expected. Analysis of the sea level data from the verification site, even after calibration for instrument drift, led to the discovery of inconsistencies between the different sea level datasets. This problem is illustrated in Figure 6, which displays the differences between the different tide gauge sea level measurements at the time of the TOPEX/Poseidon overflights. At times these differences can be over $5 \mathrm{~cm}$. Both Figures $6 \mathrm{~b}$ and $6 \mathrm{c}$ display what appears to be an annual cycle $(1$ year $=36.9$ TOPEX/Poseidon repeat cycles) with a minimum around March. Figure $6 \mathrm{~d}$, which compares the NOAA N bubbler and the $\mathrm{CU}$ pressure transducers, shows no obvious variation. The average sea state is typically highest during the winter and early spring when Pacific storms are most frequent in this region. The most pronounced differences between the tide gauges occur 

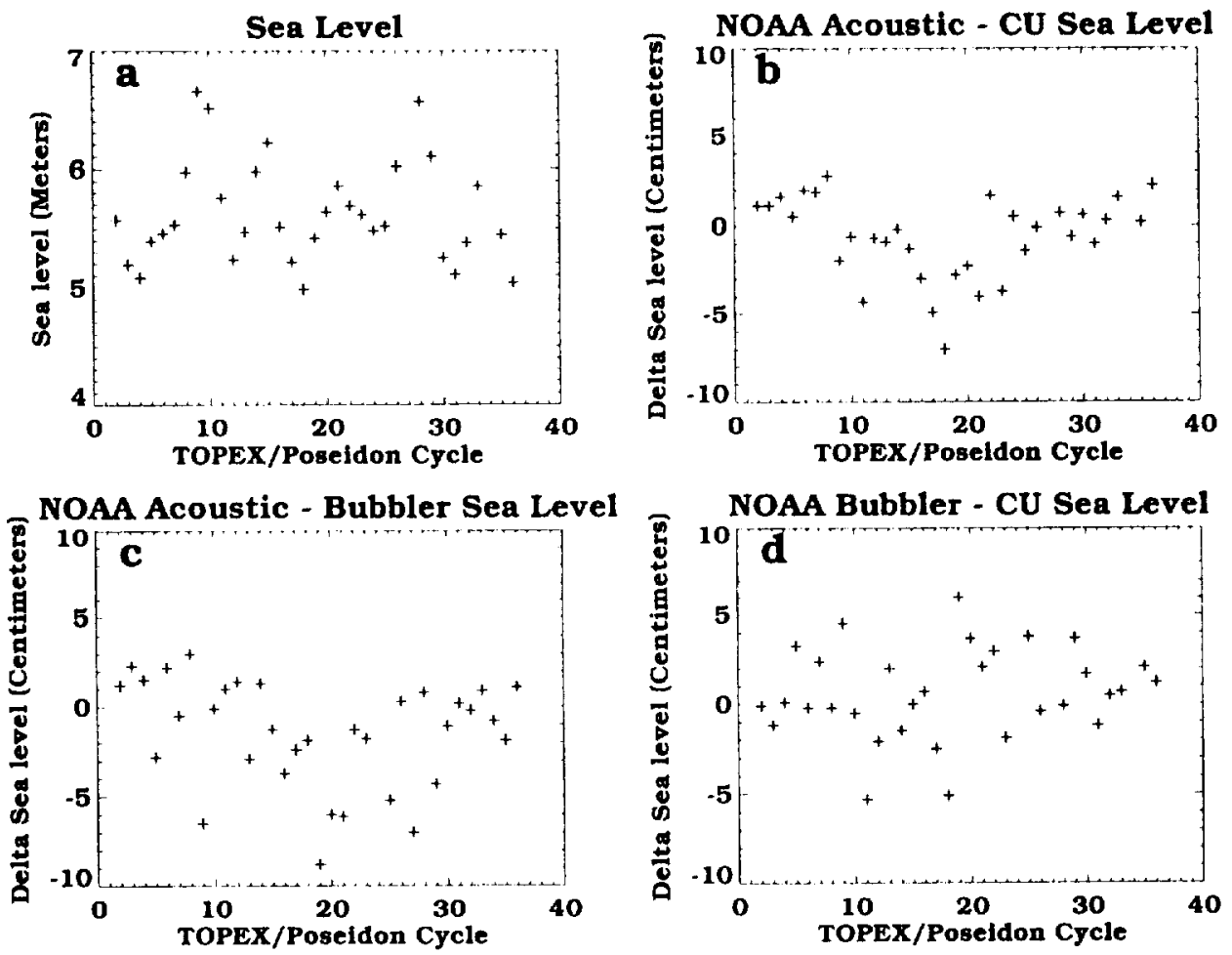

Figure 6. (a) Sea level at Platform Harvest during the satellite overflights as a function of TOPEX Poseidon cycle. Note that sea level is measured downward (an overtlight during a high tide = low value). (b) Difference between NOAA/NOS acoustic and CU pressure transducer sea level at the overflight times. (c) Difference between NOAA/NOS acoustic and NOAA/NOS N, bubbler sea level at the overflight times. (d) Difference between the NOAA/NOS N, bubbler and CU pressure transducer sea level at the overfight times.

during this period. The observed differences between the measurement systems are believed to be related to high sea state.

As these sea level data are collected continuously, it has been possible to study the response of the different tide gauges in detail. The magnitude of these differences varies on time scales ranging from hours to weeks. As discussed by Parke and Gill (1995), at least some of these inconsistencies are now understood and empirical corrections have been developed. However, the $1.0-\mathrm{cm}$ variable error assumed for instrument noise may still be underestimated.

Including additional overflights will reduce the variable errors but not the fixed errors. After consideration of the potential error sources related to the in situ measurements at the verification site, the expected accuracy of the in situ measurements for one overflight is better than $3.5 \mathrm{~cm}$. When the estimated errors in the altimeter measurement and altimeter orbit (Table 4) are included, the projected error in comparing the altimeterderived height with the in situ-derived height is $5.2 \mathrm{~cm}$ for a single overtlight. This error decreases as the number of overflights increases (see Table 5). 
Table 4

Laser tracking and altimetry errors for a single overflight

\begin{tabular}{|c|c|c|}
\hline \multirow[b]{2}{*}{ Source } & \multicolumn{2}{|c|}{ RSS Error $(\mathrm{cm})^{\prime \prime}$} \\
\hline & Fixed & Variable \\
\hline Instrument & - & 2.0 \\
\hline Dry tropospheric correction & 0.0 & 0.7 \\
\hline Wet tropospheric correction & 0.5 & 0.5 \\
\hline lonosphere correction & 1.0 & 0.5 \\
\hline EM-bias & 1.4 & 1.4 \\
\hline Skewness & 0.0 & 1.0 \\
\hline Total altimetry error & $1.8^{\prime \prime}$ & 2.8 \\
\hline $\begin{array}{l}\text { Orbit height error from } \\
\text { laser tracking }\end{array}$ & 2.0 & 1.0 \\
\hline RSS total & 2.69 & 2.97 \\
\hline
\end{tabular}

"Does not include altimeter bias. Assumes a 1-s average observation.

\section{Conclusions}

A prelaunch error budget was developed to quantify the expected observational errors at the NASA verification site prior to the installation of the instrumentation (and satellite launch). Of the parameters measured, we were surprised by the difficulty in obtaining consistent sea level measurements from different tide gauge systems in (relatively) deep water. Fortunately, the redundant systems installed at the platform provided an opportunity to study the effects and estimate a correction for the measured sea level values (see Parke and Gill, 1995).

Table 5

Expected error as a function of number of overflights

\begin{tabular}{lcc}
\hline $\begin{array}{l}\text { Number of } \\
\text { overflights }\end{array}$ & $\begin{array}{r}\text { Total RMS error } \\
(\mathrm{cm})^{\alpha}\end{array}$ & $\begin{array}{c}\text { Variable error } \\
\text { contribution }(\mathrm{cm})^{\alpha}\end{array}$ \\
\hline 1 & 5.2 & 3.9 \\
3 & 4.9 & 3.6 \\
5 & 4.6 & 3.1 \\
10 & 4.1 & 2.3 \\
20 & 3.8 & 1.7 \\
30 & 3.7 & 1.4 \\
\hline
\end{tabular}

"Includes contributions from the in situ measurements, laser tracking, and altimetry. The method includes estimation of bias and bias drift. 


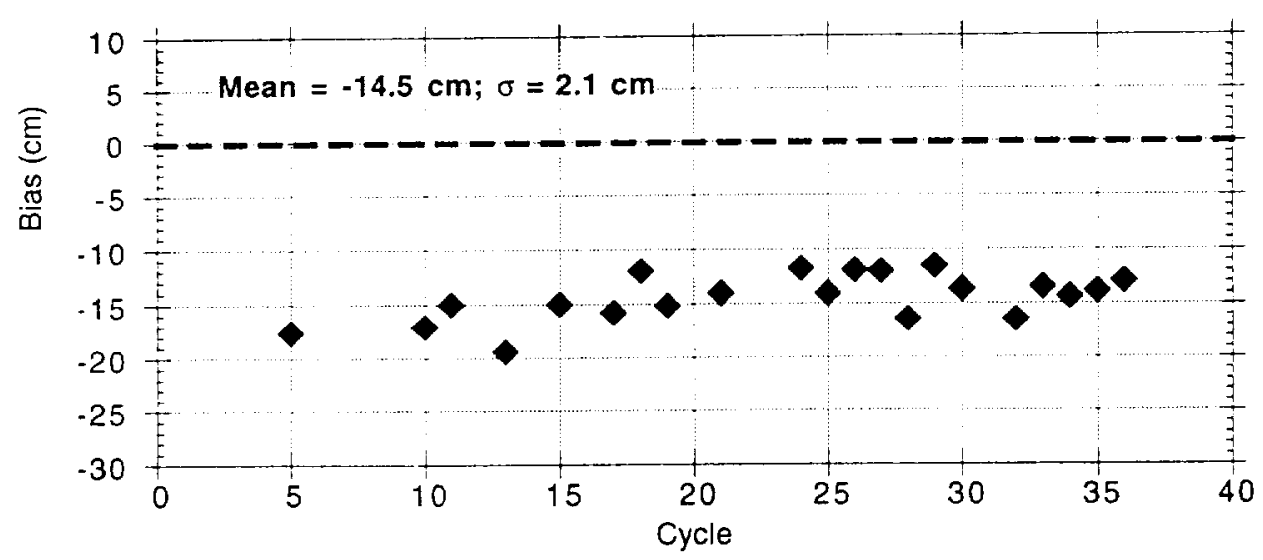

Figure 7. NASA Altimeter bias results obtained at Platform Harvest. From Christensen et al., 1994. See text for discussion.

Although the instrumentation does not provide a direct estimate of the actual error of the combined in situ measurements at the verification site, the altimeter bias closure results do provide an estimate of whether the prelaunch error budget was realistic. Christensen et al. (1994) obtained an estimate for the bias of the NASA altimeter of -14.5 $\pm 2.1 \mathrm{~cm}$ from 21 TOPEX/Poseidon overflights (see Figure 7). These results are based on GPS orbits and the NOAA/NOS acoustic tide gauge sea level measurements (corrected for sea state). Only 21 overflights were included in the analysis because the GPS orbits are not always available. The negative value indicates that the NASA altimeter is measuring short (higher sea level) in comparison to the in situ measurements. The consistency of these results indicates that the error budget for the verification site measurements is reasonable.

There have been the expected problems experienced by most in situ data collection systems, including communication difficulties (which were resolved) and occasional equipment failures. Despite these problems, Platform Harvest verification site has successfully supported, as of May 1994, 60 overflights of the TOPEX/Poseidon satellite.

\section{References}

Christensen, E. J., L.-L. Fu, and M. E. Parke. 1989. TOPEX/Poseidon altimeter, orbit, and sea level verification. Proceedings of OCEANS' 89.

Christensen. E. J., and Y. Menard (eds.). 1992. TOPEXIPoseidon Joint Verification Plan, JPL Document 92-9.

Christensen, E. J., B. J. Haines, S. J. Keihm, C. S. Morris, R. A Norman, G. H. Purcell, B. G. Williams, B. C. Wilson. G. H. Born, M. E. Parke, S. K. Gill, C. K. Shum, B. D. Tapley, R. Kolenkiewicz, and R. S. Nerem. 1994. Calibration of TOPEX/Poseidon at Platform Harvest, Journal of Geophysical Research $99: 24465-24485$.

Francis. C. R. 1993. The height calibration of the ERS-1 radar altimeter. Proceedings First ERSI Symposium-Space at the Service of our Environment. ESA SP-359: 381-393. 
Gill, S. K., R. F. Edwing. D. F. Jones, T. N. Mero, M. K. Moss, M. Samant, H. H. Shih, and W. M. Stoney. 1995. NOAA/National Ocean Service Platform Harvest instrumentation. Marine Geodesv 95:49-67.

Keihm. S. J., and C. S. Ruf. 1995. Role of water vapor radiometers for in-flight calibration of the TOPEX microwave radiometer. Marine Geodesy 95:139-156.

Kolenkiewicz, R., and C. F. Martin. 1982. SEASAT altimeter height calibration. Journal of Geophysical Research 95:3189-3197.

Kubitschek, D. G., M. E. Parke, G. H. Born, J. Johnson, and C. McLaughlin. 1995. CU sea level system at Platform Harvest. Marine Geodesy 95:69-83.

Menard, Y., E. Jeansou, and P. Vincent. 1994. Calibration of the TOPEX/Poseidon altimeters over Lampedusa additional results over Harvest, Journal of Geophysical Research 99:2448724504.

Parke, M. E., and S. K. Gill. 1995. On the sea state dependence of sea level measurements at Platform Harvest. Marine Geodesy 95:105-116.

Purcell. G. H., S. J. DiNardo, Y. Vigue, D. C. Jefferson, and S. M. Lichten. 1995. GPS measurements of the baseline between Quincy and Platform Harvest. Marine Geodesy 95:3947.

Zieger, A. R., G. C. Cleven, E. S. Davis, F. S. Soltis, and C. L. Purdy. 1995. Satellite/sensors for monitoring Earth's oceans from space. Marine Geodesy 95:1-24. 
